\title{
Leaders
}

\section{The medicolegal aspects of automatism in mild head injury}

Automatism or automatic behaviour was originally described in the Hippocratic corpus in relation to sleepwalking and other nocturnal behaviours. ${ }^{1}$ Despite its long history, this area of automatism remains confused and imprecise in the medical and legal literature. Within English common law, it is a fundamental principle that the intent (mens rea) and the act (actus reus) must occur together to constitute the crime. ${ }^{2}$ As such, the absence of a mens rea means that the person at that point in time lacks the intent to commit a crime.

In the legal view, post-traumatic automatism is a form of "sane" automatism because it results from an external factor, for example, a blow to the head, rather than from a disease of the mind (which is responsible for "insane" automatisms). ${ }^{3}$ As a legal defence under English law, if successful, post-traumatic automatism leads to acquittal rather than the judge deciding the disposal as in the case of insane automatism.

In recent years, a number of cases of footballers appearing before disciplinary tribunals for striking and other charges have claimed in their defence that they suffered a prior concussive injury and at the time of the alleged incident were suffering from a "post-traumatic automatism" and as a result were not responsible for their actions. In one celebrated case in Australian football, this defence was successful and resulted in the sport's administrative body developing specific guidelines to outlaw this potential defence. This topic of post-traumatic automatism has only a limited amount of published information to guide practitioners, players, administrators, and lawyers and this paper seeks to establish appropriate medical guidelines in this area.

\section{The medical view of post-traumatic automatism}

Automatism may be defined as "the existence in any person of behavior of which he is unaware and over which he has no conscious control" . ${ }^{6}$ It has also been defined without reference to consciousness simply as "... involuntary movement of the limbs or body of a person ...”. Posttraumatic automatism implies the presence of a head injury and subsequent amnesia for the automatic events that occur during its existence.

Fenwick more specifically defines automatism as "an involuntary piece of behavior over which the individual has no control. The behavior is usually inappropriate to the circumstances and may be out of character for the individual. Afterward the individual may have no recollection ... of his actions ..."?

Although the definition of automatism has been established, in the setting of head injury it implies a disturbance of consciousness that is often imprecise in nature. Normal consciousness necessitates an intricate and complex relation between the various components of the brain and the environment. The limits of consciousness are hard to define satisfactorily and quantitatively and we can only infer self awareness in others by their appearance and their acts.

The legal view of post-traumatic automatism Although the medical and English legal definitions of automatism differ slightly, ${ }^{7}$ in courtrooms the legal one clearly takes precedence. The most accepted legal definition is that given by Viscount Kilmuir LC in the House of Lords appeal in the case of Bratty v Attorney General for Northern Ireland. This case involved a defence of automatism caused by epilepsy. He ruled that "... the state of a person who though capable of action, is not conscious of what he is doing ... it means unconscious, involuntary action and it is a defense because the mind does not go with what is being done ...". In the same case, Lord Denning said: "... no act is punishable if done involuntarily and an involuntary act in this context ... means an act which is done by muscles without any control by the mind ... a reflex action ... or an act done by a person who is not conscious of what he is doing, such as an act done whilst suffering a concussion ... However to prevent confusion it is to be observed that in the criminal law an act is not to be regarded as an involuntary act simply because the actor does not remember it ..." (Bratty v Attorney General for Northern Ireland: [1961] 46 Cr. App. R. 1, 7, 8. AC 401)

\section{Traumatic brain injury and concussion}

Traumatic brain injury encompasses a spectrum of injury ranging from mild to severe. This injury spectrum is usually subdivided according to the Glasgow Coma Score, which is a standardised score administered at six hours post-injury. ${ }^{8}$ A mild injury would score $13-15$, a moderate injury $8-12$, and a severe injury $<8$. This scale is largely dependent on the patient's level of conscious state. Consumption of alcohol may be a confounding factor in accurately assessing such a scale.

Mild brain injury may be subclassified further and the term "concussion" is often used to describe the mild end of this injury subtype. Such injuries are commonly seen in sport, following falls or assaults, and after motor vehicle crashes. It is important therefore to clarify what is meant by concussion and how the behaviour of such a patient reflects the clinical stages of recovery from such an injury.

The Committee on Head Injury Nomenclature of the Congress of Neurological Surgeons has developed a definition of concussion. The American Medical Association and the International Neurotraumatology Association have subsequently endorsed this "consensus" definition of concussion, which has now become the accepted definition by most researchers in this field. ${ }^{910}$ The Congress of Neurological Surgeons definition states that concussion is "... a clinical syndrome characterised by the immediate and transient post-traumatic impairment of neural function such as alteration of consciousness, disturbance of vision or equilibrium due to mechanical forces".

\section{The clinical "stages" of concussion}

There is a relatively limited range of clinical symptoms and psychological effects that is seen following a concussive injury. The subject usually passes through a series of stereotyped stages of recovery. ${ }^{11}$ The typical sequence of recovery from a concussive injury would be as follows:

Stage 1: Immediately post-injury - There may be a period of unconsciousness for seconds or minutes but the subject usually awakens spontaneously. On waking, there may be little in the way of retrograde memory disturbance (that is, memory loss prior to the accident) although this becomes 
more prominent in the ensuing minutes to hours. The subject may be unsteady if attempting to stand. If questioned the subject will appear confused and disorientated. He or she will not be capable of responding to questions or commands. If an observer approaches the subject in this phase, the subject usually repetitively says "what happened" every few seconds and is incapable of understanding any explanation. Some purposeless motor activity may be present. This motor phenomenon is often termed "cerebral irritability". This stage lasts for a variable period of time but generally has recovered by 20 to 30 minutes post-injury. In the stage of post-traumatic amnesia, a subject may show automatisms.

Stage 2: Following recovery of post-traumatic amnesia-Once the period of acute post-traumatic amnesia has resolved (over 20-30 minutes) the subject is then capable of responding to command, is orientated to time, place, and person, and will be able to remember information presented to him. Any unsteadiness will have resolved by this time. The subject may report headache, blurred vision, and/or nausea at this time. Headache is a universal although non-specific symptom post-injury. If neuropsychological testing is performed at this time, characteristic deficits such as slowed information processing, will be evident.

Stage 3: Clinical recovery-The acute symptoms (headache, nausea, etc) settle over several days. During this period, the memory functions normally although the subject continues to show deficits on formal neuropsychological testing. Such deficits may not be obvious to an observer or often to the patients themselves.

Stage 4: Cognitive recovery-The clinical symptoms have fully resolved by this time and the neuropsychological function returns to normal over a variable period, depending upon the severity of injury, but typically would vary from 3-4 days for a mild concussion up to 2-3 weeks for a severe concussion.

Ritchie Russell ${ }^{12}$ made a number of observations about the clinical phenomenon of concussion and automatic behaviour. He described a stage of "cerebral irritation" that: "... is seen in all degrees of concussion. The concussed football player often moves his limbs restlessly or talks meaninglessly, and not a few cases of head injury are violent and abusive when seen in the outpatient department. Though in slight injuries, the duration of this stage is brief when compared to what may be seen in severe cases, it seems that the condition has the same significance in both types of case. In the stage of irritability, consciousness is not fully recovered and the patients have no subsequent recollection of their actions. It is probable that these irritable states merely represent a stage in the recovery of consciousness. The mental and higher cerebral functions have not yet recovered, and owing to the lack of their control, the more primitive and less vulnerable motor activity is running wild ..."

In medical parlance, Russell's concept of "cerebral irritability" reflects the legal parlance of a post-traumatic automatism.

\section{Automatism in the setting of concussion}

Although not well studied in this setting, the consensus of expert opinion would regard "automatism" or irritability following concussion to be typically manifest by signs such as:

- Thrashing or flailing limbs in a non-directed manner

- Refusing to be directed (for example, onto a stretcher or into an ambulance)

- Wildly swinging arms if directly confronted or restrained

- Aimless wandering in a "robotic" fashion.
Furthermore, any automatisms by definition could only occur during the phase of post-traumatic amnesia following the trauma. This period usually resolves over 20-30 minutes following a typical concussive injury. Posttraumatic automatisms do not encompass goal directed or purposeful activity. The typical occurrence is a concussed footballer rolling about on the ground or attempting to try and get up and who is incapable of following directions to get onto a stretcher. If such a player does get to his feet an observer may describe them as resembling a robot or automaton staggering around but with no purpose. ${ }^{13}$ In many ways, the increasing complexity of behaviour directly reflects more specific intent in that specific activity.

In practice, establishing a defence of post-traumatic automatism depends largely on a thorough knowledge of the clinical and neuropsychological features of mild brain injury, clinical assessment, and review of the evidence. Transcripts of witness statements, police interviews, especially if video or audiotaped, and contemporaneous notes by police or medical staff often provide the most useful sources of information on which an opinion in this regard may be based.

The criteria that would need to be established to prove a defence of epileptic automatism were originally proposed by Fenwick ${ }^{7}$ and modified by Wright and colleagues. ${ }^{14}$ In this paper, we propose a more comprehensive requirement specifically for post-traumatic automatism. This should include:

(1) The presence of a documented concussive brain injury

(2) The automatism occurring in the stage of posttraumatic amnesia (Stage 1 above) as evidenced by documentation of post-traumatic amnesia or impaired memory for new learning

(3) The automatism behaviour represents a reactive and/or purposeless response to stimulation or confrontation

(4) No premeditation, planning, or concealment is demonstrable

(5) The absence of goal directed, purposeful, or proactive behaviour.

The usefulness of forensic psychiatric examinations is limited in this setting. ${ }^{15}{ }^{16}$ In the absence of intent due to post-traumatic automatism, psychiatric determination of the person's state of mind adds little to this process. Psychiatrists seldom have clinical experience of acute head injury and are ill equipped to judge the neurological aspects of this problem. Although the psychiatrist may correctly concern himself with the individual's capacity to form intent, nevertheless in the case of post-traumatic automatism, this is not usually relevant. Intent is not a psychiatric concept. ${ }^{17}$ In court, the issue of intent is usually left to the jury to determine (see R v Maloney [1985] AC 905, [1985] 1 All ER 1025, [1985] 2 WLR 648).

\section{Conclusion}

The issue of post-traumatic automatisms is complex, with different legal and medical views on the subject. Although the phenomenon of automatic behaviour is well established following epileptic seizures or in the setting of sleepwalking or other nocturnal parasomnias, the issue of post-traumatic automatisms is complex as the issue depends on a characterisation of the individual's conscious state and the stage of concussion they were in at the time of the alleged behaviour. This paper seeks to establish guidelines for the assessment of this phenomenon.

P MCCRORY

Neurologist $\mathbb{E}$ Sports Physician

31 Grosvenor Parade, Balwyn

Victoria 3103, Australia

pmccrory@compuserve.com 
1 Hippocrates. The genuine works of Hippocrates. London: The Sydenham Society, 1849

Smith J, Hogan B. Criminal law, 8th edn. London: ButterworthHeinnemann, 1996.

3 Williams G. Criminal law, 2nd edn. London: Stephens, 1961

4 Beran RG. Automatisms - the current legal position related to clinical practice and medicolegal interpretation. Clin Exp Neurol 1992;29:81-91.

5 Fenwick P. Brain, mind and behaviour. Some medico-legal aspects. $\mathrm{Br} f$ Psychiatry 1993;163:565-73.

6 Blair D. The medicolegal aspects of automatism. Med Sci Law 1977;17:16782.

7 Fenwick P. Automatism, medicine and the law. Psychol Med Monogr Suppl 1990;17:1-27.

8 Jennett B, Bond M. Assessment of outcome after severe brain damage: a practical scale. Lancet 1975;1:480-4.

9 Congress of Neurological Surgeons. Committee on Head Injury Nomenclature: Glossary of Head Injury. Clin Neurosurg 1966;12:386-94.
10 AMA. Subcommitee on classification of sports injuries. Standard nomenclature of athletic injuries. Chicago: American Medical Association, 1966

McCrory PR. Were you knocked out? A team physician's approach to initial concussion management. Med Sci Sports Exerc 1997;29(suppl 7):S207-12. 2 Russell W. Cerebral involvement in head injury. A study based on the examination of two hundred cases. Brain 1932;55:549-603.

13 McCrory P, Berkovic S. Videoanalysis of the motor and convulsive manifestations of concussion in acute sport related head injury. Neurology 2000;54: 1488-92.

14 Wright N, Lelfer D, Wright I. Automatism revisited: post-traumatic automatism as a defense to a serious criminal charge. Med Sci Law 1995;35:327-32.

15 Briscoe O. Intention at the moment of crime ... beyond reasonable doubt? Med Sci Law 1975;15:42-6.

16 Williams G. The mental element in crime. Jerusalem: Magnes Press, The Hebrew University 1965.

17 Quinn PJ, Larkin EP. Intent. Br f Hosp Med 1997;57:454-6.

\section{Performance in motor sports}

Motor racing is one of the most physically and mentally challenging of all sports, not only for racing drivers themselves, but also for the teams that play an integral role in the eventual performance of the car. It is my belief that, for such a demanding and popular sport, sports medicine is seriously underused. Drivers and teams are faced with continuous pressure to perform, yet have far less involvement with sports medicine staff than many Olympic athletes, tennis professionals, and footballers of all codes, particularly from a preventive perspective. In this article, I will outline some of my experiences as a sport psychologist and fitness consultant with racing car drivers and teams, identifying some of the challenges in a growing field.

Before going into detail, it should be noted that motor sports has depth well beyond Formula One. For example, motor racing is a major sport in the United States with Nascar, Cart World Series, and the Indy Racing League to name but a few. In Europe there is Formula 3, Formula 3000, and rallying. In Asia, there is also a huge number of categories in many countries - for example, in Australia alone there is the Shell Touring Car series, Formula Holden, Formula Ford, GTP, and Nations Cup series, and, in other parts of Asia, the Asia Pacific Rally Series and the Japanese sports car series coexist.

In almost all of the categories identified above, particularly Formula One, motor racing drivers must execute numerous motor and cognitive skills simultaneously. They must remain calm and focused on their vehicle's performance, the track, and their competitors only centimetres away, while travelling at speeds of 150-300 km per hour. They must also manoeuvre gears and foot pedals while steering their vehicle, using highly developed coordination. Each movement must be rapid and precise. During this process, drivers must also have the ability to communicate effectively with their pit manager on their headset radio and ingest fluids through their specially designed hydration systems. Pit crews, including engineers, mechanics, tyre specialists, and managers, must work as a close team, follow the instructions of a leader, and conduct their physically demanding tasks, whether it be loading fuel or changing tyres. In this sport there is no room for error. Any mistake may cost a life.

Sport psychology for motor racing teams need not be reactive, as many people perceive. Most sport psychologists, including myself, accept that a certain amount of work will be in response to crisis situations, but prefer to work in a non-reactive preventive environment. This allows skill development, team building, and equipping individuals and teams with the tools necessary to perform to their maximum. There are numerous research papers to verify the effectiveness of psychological interventions in sports. Goal setting, visualisation and imagery, anxiety control, effective communication and team building are some of the areas that can assist performance in motor sports, when tailored correctly and specifically. In my opinion any racing driver or team that does not take advantage of physical and mental professionals are themselves unprofessional.

With racing drivers specifically, setting goals and reviewing track maps to plan how to best drive a course is vital. This enables the opportunity for visualisation and imagery to take place, so that the driver has practically driven the course many times before arriving there. This can be guided imagery, where drivers can have a "perfect" lap described to them. Modern simulators also assist enormously in this area. The mind is tailored for the conditions, the car, and the strategy. Educating a driver about breathing techniques and other thought control skills for remaining calm at times of pressure, such as in qualifying and at the start of a race, also plays an integral part of psychological development. For example, there are often many people around a driver, such as sponsors, fans, and the media, before he/she gets into the car. Some drivers use the clicking of their seat belt as it fastens as a trigger to block any distractions and "switch on". At this time, deep breathing, using the force of the seat belt on the chest and stomach as a cue to relax and focus, may be used to lower heart rate and direct focus. In addition, reminding themselves of cue words developed earlier with regard to race strategy must be used. For example, "be aggressive and smooth" or "be conservative" may be used, depending on conditions. After competition, confidence, concentration, physical state, and ability to follow their plan and implement skills under pressure must be reviewed.

The individuals and teams that I have worked with discuss and record goals for the year (or season), as well as for each race meeting. These are reviewed accordingly. Potential scenarios are discussed, as well as strategies for handling them. The roles of individuals in the team and exactly who they are accountable to on the day of the race are discussed. All of these sessions are prepared in advance with the team management, who are in control of this process. Visits are also made to the workshop, so that my role is integrated with the "team".

I do travel with the team when possible, which only facilitates my education and adds to my role, particularly with the drivers. Often, however, on the day, the work encompasses observing, discussing general matters, or dealing with crises.

Recently, I travelled to hospital with a driver who had rolled his car on a corner at around $200 \mathrm{~km}$ per hour. The 
manager in the pits described how his radio had gone silent. No one in team knew what had happened or the condition of the driver. The emergency medical team (staffed by the local hospital) would not allow anyone to see him. The injury was eventually found to be a serious break in his right forearm, caused by his hand being caught in the steering wheel. The team was anxious and the driver was somewhat shaken. The team had no medical members other than myself to decide on the best course of action to follow from the advice given by the hospital.

I have also been at a race track when a death has occurred. Naturally, the race was stopped, but the next race proceeded. This creates difficulties for many people, well beyond the immediate team of the driver killed. The motor racing community is a tight knit one, and if a competitor is seriously injured, there is a ripple effect.

In addition to many of the direct challenges in this sport, there are also many indirect challenges. Raising money to drive or build a team is a difficult task. This implies many financial sacrifices in order to reach the start line, adding the pressure to not damage the car. This factor also means that many drivers are not young. In the lower categories, it is not unusual to see men in their forties participating. This financial factor also means that many drivers are part time. They are successful in business during the week, and race cars at weekends. Younger drivers who do not have sufficient funds, must adapt to performing in different lower category vehicles. This can be extremely difficult, the differences in vehicles often being considerable. This range of individual factors also influences the fitness of the driver.

Having accompanied a driver around a racing track in a racing car, I have experienced first hand some of the physical demands of the sport. Often heart rates close to maximum are endured for extended periods of time (20-60 minutes), and it is not uncommon for a driver to lose $5-10 \%$ of body weight during a race because of dehydration. Needless to say, the fitness of the driver and the team is also vital for performance. Interestingly, however, this is a sport in which it is not uncommon for the participants to smoke, and they have certainly not historically been athletic or sport oriented. Nevertheless, on race weekends, demanding physical routines are performed. Developing a fitness regimen and convincing the team management that it would be worth while for the driver and team to follow it is sometimes not an easy task. Even though the cost of incorporating a fitness programme or employing a sports medicine team is relatively low compared with the other costs associated with motor racing, such programmes have in the past not been seen as a priority. In addition, the motivation of drivers to carry out fitness training is often lacking, even though those teams and drivers that are committed to such disciplines are often successful.

Recently, ideas on the importance of the fitness and health of drivers and teams have begun to change. Positive role models from Formula One, a branch of motor sport that is beginning to take health and fitness seriously, are having some impact. This example is encouraging those involved in motor sport to think of themselves as athletes rather than "petrol heads". Although, I have not found any scientific research in the field of racing driver fitness, there is controversy about the best form of fitness training for drivers. I am aware of a case study in which a high profile driver in Europe returned to his home country during a rest period. During this time, he became friendly with a rowing team who assured him that rigorous exercise on a rowing ergometer would be excellent training for him. $\mathrm{He}$ reportedly returned fitter, but in the first practice session injured his shoulder because his moulded seat no longer fitted him because of muscle development. It is also not unheard of for engineers to ask drivers to lose weight to reduce the overall weight of the driver and vehicle combined.

Nutrition is also an area that should be considered. It is common for the food consumed during a four or five day competition not to be performance oriented. Considering the number of hours of physical work, nutrition is clearly important. From observation at race meetings, I feel that many teams have improved in this area, with sports drinks and carbohydrates replacing fast food. However, it is still not uncommon for teams to include hamburgers, sweet biscuits, and pastries in their meals during competitions.

In conclusion, in the absence of data on the topic, I would like to argue that the motor sport industry is one of the highest profile international sports with the lowest presence of sports medicine. Furthermore, physical conditioning and mental preparation for the drivers and teams are absolutely essential. Many teams would benefit from input from sports medicine professionals working in a consultative preventive way, in addition to being available in crisis situations. Finally, motor sports is a field that would benefit enormously from further research as well as from education in relation to the potential benefits from sports medicine and sports sciences.

Olympic Park Sports Medicine Centre

A J KLARICA

Swan Street, Melbourne 3004, Australia

ajklarica@yahoo.com

1 Singer R, Hausenblas H, Janelle C. Handbook of sport psychology. New York: John Wiley, 2001.

\section{What is the most appropriate treatment for patellar tendinopathy?}

Since the demise of the concept of an inflammatory basis for tendinopathy, treatment has been based on the degenerative concept. ${ }^{1}$ However, an alternative theory of a failed healing response may be more fitting, ${ }^{2}$ and treatment that maintains or encourages the healing response in the tendon is required. Currently, treatment remains empirically based, as it is not known what interventions may best stimulate a healing response.

The conservative treatment of patellar tendinopathy recorded in the literature includes combinations of rest, ${ }^{3}$ exercise, especially eccentric exercise, ${ }^{4}$ modalities including ultrasound, heat, and cryotherapy, ${ }^{5}$ frictions, ${ }^{6}$ biomechanical adjustment, ${ }^{7}$ and pharmaceutical treatment. ${ }^{8}$ Many of these treatments are based on "clinical experience" rather than appropriately analysed data.

The surgical management of patellar tendinopathy includes several different operative procedures and postoperative rehabilitation protocols. The choice of surgical treatment of patellar tendinopathy appears to be based on the surgeon's preference. ${ }^{9}$ 
Recent literature reviews ${ }^{810}$ document a dearth of controlled trials in the treatment of patellar tendinopathy. Hence, a review of treatment of patellar tendinopathy that used a randomised allocation or were prospective in nature was undertaken.

Ten randomised trials were reviewed. These studies investigated the effects on the patellar tendon of antiinflammatory medication $(n=7)$, exercise $(n=2)$, and local massage $(n=1)$. No randomised surgical papers were identified, hence three prospective studies on the surgical treatment of this condition were included.

\section{Conservative treatment}

EXERCISE

Two papers ${ }^{11}{ }^{12}$ review the effect of exercise regimens on patellar tendinopathy. These studies focus on strengthening of the muscles around the knee in subjects with jumper's knee, and measuring changes in strength, pain, and function after an eight and 12 week intervention. Outcome measures varied, but both measured changes in strength and pain; one study measured function (return to sport) as well. ${ }^{11}$

A reduction in pain in the study period was apparent in one study, without quadriceps strength gains. Conversely, the other ${ }^{12}$ study showed improvement in quadriceps work in the study period, but it is unclear if there was a concurrent reduction in pain.

\section{MASSAGE/FRICTIONS}

One study ${ }^{13}$ compared treatment of patellar tendinopathy with a massage device with those treated traditionally (stretching, frictions, electrophysical modalities). The main outcome measure used in this study was a scale designed to evaluate long term changes in the patellofemoral joint, ${ }^{14}$ which may lack sensitivity to symptoms and functional changes in patellar tendinopathy. Results indicated that the main outcome measures did not differ between groups, and, although the authors concluded that the device improved clinical outcomes in patellar tendinitis, it is difficult to deduce from the data reported that the device offered a better outcome than the traditional treatment.

\section{PHARMACOTHERAPY}

Three studies investigated iontophoresis or phonophoresis using corticosteroid, ${ }^{15-17}$ two studies examined the effect of corticosteroid injection, ${ }^{18}{ }^{19}$ and two studies tested the outcome of non-steroidal anti-inflammatory drugs (one orally $^{20}$ and one transcutaneously). ${ }^{21}$

Iontophoresis with corticosteroid improved outcome in the treatment group, whereas phonophoresis with corticosteroid showed no difference in outcome when compared with phonophoresis with placebo.

The studies that used injection indicated a good response to this intervention. The study of Capasso et $a l^{18}$ indicated that aprotinin offered a better outcome than either corticosteroid or placebo. The use of non-steroidal anti-inflammatory drugs for tendon pain appears to be warranted in subjects with short term symptoms.

\section{Surgical treatment}

There have not yet been any randomised studies of surgical treatment in patellar tendinopathy. Three studies have a clear prospective design. Khan et al ${ }^{22}$ showed that $73 \%$ of the subjects that underwent surgery for patellar tendinopathy had good results. Panni et $a l^{23}$ included both conservative and surgical treatment in their study. Subjects who had failed the conservative treatment were operated on, and all of these subjects were reported to have good or excellent outcome.
Testa et $a l^{4}$ investigated the efficacy of percutaneous tenotomy, and reported that the technique is more effective in mid-tendon pathology than in proximal tendon pathology. This study reported that nearly $40 \%$ of subjects had poor results, and isokinetic testing showed persistent strength deficits across all outcomes.

\section{Discussion}

It is surprising that so few studies in patellar tendinopathy have a randomised or prospective design, and the few papers in this series have raised several issues in study design.

\section{DIAGNOSTIC CRITERIA}

Most authors used clinical assessment for diagnosis without confirmatory imaging. Pain and palpation tenderness were almost exclusively used, only two studies documented using pain on resistance of muscle contraction or other functional testing. ${ }^{15}{ }^{16}$ As tendon pain does not refer widely, the exact location of the pain would add important diagnostic accuracy to these tests.

It can be argued that imaging is not necessary to diagnose patellar tendinopathy, as the presence of abnormal imaging does not indicate absolutely that the pain is coming from the tendon. ${ }^{25}{ }^{26}$ There is also an argument for "imaging normal" patellar tendinopathy, ${ }^{27}$ although this remains a contentious issue among tendon researchers.

Despite these arguments, confirmation of pathology within the tendon in conjunction with clinical tests would guarantee that the best diagnostic criteria are used, and future studies should include imaging as part of the spectrum of tests needed to confirm the diagnosis.

Palpation is used as both a diagnostic criterion and an outcome measure in this series of studies. Thus it is important that palpation is both a reliable and valid test for patellar tendinopathy. Palpation is a reliable test, but not necessarily a valid diagnostic test for this condition, ${ }^{28}$ as it does not correlate with either imaging changes or symptoms.

Therefore, there is no specific criterion for the diagnosis of patellar tendinopathy, and the criteria used in future studies should include symptoms with objective or functional muscle testing, the pain documented on a pain map, and diagnostic imaging.

\section{LENGTH OF SYMPTOMS}

Length of symptoms before intervention also varied widely, some studies excluding those tendons with long term symptoms (subjects with symptoms for less than five days $^{20}$ ) whereas other studies excluded those with short term symptoms (subjects with symptoms for longer than six month ${ }^{23}$ ). It could be argued that these two opposing exclusion criteria are therefore investigating subjects with different conditions.

Studies that exclude long term symptoms risk including tendons without overuse tendinopathy, and the efficacy in these studies (using anti-inflammatory intervention) may be because a true tendinopathy does not exist and because of an inflammatory component to the subjects' pain. Combined with the poorly documented and restricted diagnostic criteria, it is possible that these subjects do not have tendon mediated pain. Short term tendon pain (what this is pathologically is unknown) is not a management problem, as it appears from this series to respond well to anti-inflammatory medication. Studies of treatment efficacy should be directed at tendons that have long term symptoms, as it is these that constitute the difficult to manage group. 
STUDY NUMBERS

Four studies that examined the effect of corticosteroids on tendinopathy used subjects with symptoms in several body sites. This may make the conclusions drawn about effectiveness of anti-inflammatory drugs less valid for patellar tendinopathy.

In the remaining studies the subject numbers were relatively small: only one study had more than 100 subjects, and the remaining studies had less than 50 . It is possible that these studies would have a type 2 statistical error.

STUDY LENGTH, TREATMENT, AND FOLLOW UP

The treatment protocol was very short in most studies (less than three weeks in six studies), except for those studies investigating exercise as an intervention (six to eight weeks). Only one study extended the follow up beyond the end of treatment, ${ }^{18}$ and evaluated subjects 12 months after treatment was completed. As patellar tendinopathy is a recurrent condition, ${ }^{29}$ these studies provide no evidence that there is any long term efficacy for any of these treatments.

\section{OUTCOME MEASURES}

Outcome measures are all subjective in patellar tendinopathy. Authors used unvalidated ${ }^{16}$ or adapted knee pain scales, ${ }^{12}$ scales not specifically designed for tendinopathy, ${ }^{13}$ or generic tendon scales ${ }^{30}{ }^{31}$ that are not necessarily appropriate or specific for the patellar tendon. The outcome scale used in both conservative and surgical papers (excellent, good, fair, poor) ${ }^{32}$ lacks specificity and sensitivity in quantifying outcome after treatment for patellar tendinopathy.

The use of palpation as an outcome measure raises similar problems to its use as a diagnostic test for patellar tendinopathy. There is no evidence that tenderness to palpation is a valid outcome measure. The use of a gauge to standardise and quantify palpation tenderness ${ }^{33}$ may improve the validity of this outcome measure; however, normative data for tendons are required.

\section{CONCURRENT TREATMENT}

Most of the studies had either controlled ${ }^{112}$ or uncontrolled $^{1617}$ treatment or exercise during the study period that may have influenced outcome. Uncontrolled exercise was not described, as prescription was based on the individual response to treatment. In only three studies ${ }^{15} 2021$ were the subjects specifically requested to refrain from other treatments and exercise.

\section{Conclusions}

\section{CONSERVATIVE TREATMENT}

Studies of patellar tendinopathy have been consistently reported in the literature for 30 years. Many of these studies have suggested that it is resistant to treatment and recurrent in nature. ${ }^{29}$ Similarly, many authors suggest the need to exhaust conservative treatment options before proceeding to surgery. ${ }^{34}$ Despite this, there are only three studies that have investigated conservative nonpharmaceutical intervention. Hence more studies on the conservative treatment of patellar tendinopathy are needed. From the literature reviewed for this paper, it is impossible to suggest that any one conservative treatment is more appropriate than any other to treat patellar tendinopathy.

\section{SURGICAL TREATMENT}

No studies on the surgical treatment of patellar tendinopathy fully met the criteria outlined in the methods section. When prospective studies were included, only three surgical studies were appropriate to review, all with relatively small subject numbers. None of the studies offers great insight as to the effectiveness of surgery on this tendon.

Coleman et $a l^{9}$ reviewed 25 patellar tendon surgery papers and identified the methodological flaws in many of them. Their criticisms of the literature included: the nature of the studies (mainly retrospective case series); bias in subject recruitment and data collection; insensitive outcome measures (Kelly system ${ }^{32}$ ); and the postoperative regimens (variable).

Similarly to conservative treatment, the literature does not offer any indication of the effectiveness or otherwise of surgical treatment of patellar tendinopathy.

\section{Summary}

Patellar tendinopathy affects athletes in many sports and at all levels of participation, but has a particular affinity for elite, jumping athletes. These athletes can endure months of frustratingly slow rehabilitation, with treatment that appears to be based on little else other than the personal experience of the treating practitioner.

The studies examined in this review indicate that it is impossible to recommend any treatment for this condition. Until many more studies are completed, both athletes and clinicians will remain frustrated with the limited treatment options that have been shown to have a beneficial effect on patellar tendinopathy.

Musculoskeletal Research Centre

J L COOK

La Trobe University, Bundoora

Victoria 3086, Australia

7.Cook@latrobe.edu.au

Department of Family Practice and School of Human Kinetics

K M KHAN

University of British Columbia, Canada

kkhan@interchange.ubc.ca

1 Perugia L, Postacchini F, Ippolito E. The tendons. Biology, pathology, clinical aspects. Milano: Editrice Kurtis srl, 1986.

2 Clancy W. Failed healing responses. In: Leadbetter W, Buckwater J, Gordon $\mathrm{S}$, eds. Sports-induced inflammation: clinical and basic science concepts. Park Ridge, IL: American Orthopedic Society for Sports Medicine, 1989.

3 Ferretti A, Puddu G, Mariani P, et al. The natural history of jumper's knee: patellar or quadriceps tendinitis. Int Orthop 1985;8:239-42.

4 Curwin S. The aetiology and treatment of tendinitis. In: Harries M, Williams C, Stanish WD, Micheli LJ, eds. Oxford textbook of sports medicine. Oxford: Oxford University Press, 1994.

5 Molnar T, Fox J. Overuse injuries of the knee in basketball. Clin Sports Med 1993;12:349-62.

6 Cyriax J. Textbook of orthopaedic medicine: treatment by manipulation, massage and injection. London: Bailliere Tindall, 1984

7 Kannus P. Etiology and pathophysiology of chronic tendon disorders in sport. Scand $\mathcal{F}$ Med Sci Sports 1997;7:78-85.

8 Fredberg U, Bolvig L. Jumper's knee. Scand f Med Sci Sports 1999;9:66-73. 9 Coleman BD, Khan KM, Maffulli N, et al. Studies of surgical outcome after patellar tendinopathy: clinical significance of methodological deficiencies and guidelines for future studies. Scand f Med Sci Sports 2000;10:2-11.

10 Almekinders L, Temple J. Etiology, diagnosis, and treatment of tendonitis: an analysis of the literature. Med Sci Sport Exerc 1998;30:1183-90.

11 Cannell LJ. The effects of an eccentric-type exercise versus a concentrictype exercise in the management of chronic patellar tendonitis. [Masters Thesis]. Vancouver: University of British Columbia, 1982.

12 Jenson K, Di Fabio RP. Evaluation of eccentric exercise in treatment of patellar tendinitis. Phys Ther 1989;69:211-16.

13 Wilson JK, Sevier TL, Helfst R, et al. Comparison of rehabilitation methods in the treatment of patellar tendinitis. Fournal of Sports Rehabilitation 2000; 9:304-14.

14 Karlsson J, Thomee R, Sward L. Eleven year follow-up of patello-femoral pain syndrome. Clinical fournal of Sports Medicine 1996;6:22-6.

15 Klaiman MD, Shrader JA, Danoff JV, et al. Phonophoresis versus ultraound in the treatment of common musculoskeletal conditions. Med Sci Sports Exerc 1998;30:1349-55.

16 Pellecchia G, Hamel H, Behnke P. Treatment of infrapatellar tendinitis: a combination of modalities and transverse friction massage versus iontophoresis. Fournal of Sport Rehabilitation 1994;3:315-45.

17 Penderghest C, Kimura I, Gulick D. Double-blind clinical efficacy study of pulsed phonophoresis on perceives pain associated with symptomatic tendinitis. fournal of Sport Rehabilitation 1998; 7:9-19.

18 Capasso G, Testa V, Maffulli N, et al. Aprotinin, corticosteroids and normosaline in the management of patellar tendinopathy in athletes: a pronormosaline in the management of patellar tendinopathy in athletes: a pro

19 Pfeiffer-Jensen M, Fredberg U, Clemmensen D, et al. Pain assessment in inflamed tendons before and after placebo and local glucocorticoid treatment. Scand $\mathcal{F}$ Rheumatol 1998;108:146. 
20 Lecomte J, Buyses H, Taymans J, et al. Treatment of tendinitis and bursitis: a comparison of nimesulide and naproxen sodium in a double blind parallel trial. Eur 7 Rheumatol Inflamm 1994:14:29-32.

21 Dreiser RL, Ditisheim A, Charlot J, et al. A double blind, placebo controlled study of niflumic acid gel in the treatment of acute tendinitis. Eur F Rheumatol Inflamm 1991;11:38-45.

22 Khan KM, Visentini PJ, Kiss ZS, et al. Correlation of US and MR imaging with clinical outcome after open patellar tenotomy: prospective and retrospective studies. Clinical fournal of Sports Medicine 1999;9:129-37.

23 Panni A, Tartarone M, Maffuli N. Patellar tendinopathy in athletes. Outcome of nonoperative and operative management. Am $\mathcal{F}$ Sports Med 2000;28:392-7.

24 Testa V, Capasso G, Maffulli N, et al. Ultrasound guided percutaneous longitudinal tenotomy for the management of patellar tendinopathy. $\mathrm{Med} S \mathrm{Sc}$ Sport Exercise 1999;31:1509-15.

25 Cook J, Khan K, Kiss ZS. Patellar tendinitis: the significance of magnetic resonance imaging findings [letter]. Am $\mathcal{F}$ Sports Med 1999;27:831.

26 Cook JL, Khan KM, Harcourt PR, et al. Patellar tendon ultrasonography in asymptomatic active athletes reveals hypoechoic regions: a study of 320 asymptomatic active athletes reveals hypoechoic regions:
tendons. Clinical fournal of Sports Medicine 1998;8:73-7.
27 Shalaby M, Almekinders LC. Patellar tendinitis: the significance of magnetic resonance imaging findings. Am $\mathcal{F}$ Sports Med 1999;27:345-9.

28 Cook J, Khan K, Kiss ZS, et al. Reproducibility and clinical utility of tendon palpation to detect patellar tendinopathy in young basketball players. $\operatorname{Br} \mathcal{F}$ Sports Med 2001;35:65-9.

29 Cook JL, Khan K, Harcourt PR, et al. A cross-sectional study of 100 cases of jumper's knee managed conservatively and surgically. Br F Sports Med 1997;31:332-6.

30 Blazina M, Kerlan R, Jobe F, et al. Jumper's knee. Orthop Clin North Am 1973;4:665-78.

31 Curwin S, Stanish WD. Tendinitis: its etiology and treatment. Lexington: Collamore Press, 1984

32 Kelly DW, Carter VS, Jobe FW, et al. Patellar and quadriceps rupturesjumper's knee. Am F Sports Med 1984;12:375-80.

33 McCarty D, Gatter R, Phelps P. A dolorimeter for quantification of articular tenderness. Arthritis and Rheumatology 1965;8:551-9.

34 Colosimo AJ, Bassett FH. Jumper's knee: diagnosis and treatment. Orthop Rev 1990;29:139-49.

\section{The last "oxygenless" ascent of Mt Everest}

Our continued fascination with the element oxygen $\left(\mathrm{O}_{2}\right)$, first discovered by Joseph Priestley (1733-1804), is eminently justified, for without it we would simply not survive. Photosynthesis breathes life into what was 1000 million years ago considered to be a reductive atmosphere containing only $1-2 \% \mathrm{O}_{2}$. Contemporary estimates now suggest that the green plants on earth combine a total of 150 billion tons of carbon (from $\mathrm{CO}_{2}$ ) with 25 billion tons of $\mathrm{H}_{2}$ (from $\mathrm{H}_{2} \mathrm{O}$ ) to liberate 400 billion tons of $\mathrm{O}_{2}$ each year, thus accounting for the present day atmospheric content of $\mathrm{O}_{2}(20.9 \%)$, which has persisted for the last one tenth of the Earth's existence. ${ }^{1}$

Few are more acutely aware of the importance of the elixir of life than mountaineers when exposed to the innocuous effects of hypobaric hypoxia during ascent to terrestrial high altitude. Since the French mathematician Blaise Pascal (1623-1662) first showed that barometric pressure (and hence the inspired partial pressure of $\mathrm{O}_{2}$ $\left.\left(\mathrm{PIO}_{2}\right)\right)$ decreased with altitude, scientists have developed a fascination with the maximal altitude that humans could achieve without the unsporting assistance of supplemental $\mathrm{O}_{2}$. The ensuing battle between scientific prediction and human performance soon blossomed into one of the most colourful sagas in the history of high altitude mountaineering and physiology. ${ }^{2}$

The aristocratic Italian climber, the Duke of Abruzzi, rocked the scientific world at the turn of the last century by completing an "oxygenless" ascent to $7500 \mathrm{~m}$ in the Karakoram despite ominous predictions by the British Alpine Club, " . .21 $500 \mathrm{ft}(6553 \mathrm{~m})$ is near the limit at which man ceases to be capable of slightest further exertion." ${ }^{3}$ Naturally, it was not long before attention turned towards Mt Everest, which in 1892 had been declared the highest mountain in the world. Mountaineers were irrevocably drawn to the ultimate challenge, and, in 1924, Edward Norton (1884-1954) ascended to within $300 \mathrm{~m}$ of its summit without supplementary $\mathrm{O}_{2}$, a remarkable feat eclipsed by the untimely deaths of George Mallory and Andrew Irvine some two days later.

These courageous attempts motivated a series of pioneering studies by Rodolfo Margaria (1901-1983) and Joseph Barcroft (1872-1947), who subsequently concluded that an oxygenless ascent of Mt Everest would not be possible. ${ }^{4}$ However, the epochal ascent by Reinhold Messner and Peter Habeler in 1978 put paid to their gloomy predictions; the last 3\% of Mt Everest had finally been conquered 54 years after Norton's initial bid, having claimed no fewer than 39 lives in the process. Messner's quote on reaching the top clearly establishes that the summit of Mt Everest was tantalisingly close to the limits of human tolerance, ". . . Now, after the hours of torment ... I have nothing more to do than breathe .. .I am nothing more than a single, narrow, gasping lung, floating over the mists and the summits." By 1986, Messner had confirmed his place in mountaineering history having climbed all 14 of the $8000 \mathrm{~m}$ giants without supplementary $\mathrm{O}_{2}$.

The physiological significance of these achievements came to light a decade later when two landmark studies ${ }^{6}$ measured the maximal oxygen uptake $\left(\mathrm{VO}_{2} \mathrm{MAX}\right)$ of healthy volunteers on the summit at a mere $1.07-1.17$ litres $/ \mathrm{min}$ or $15 \mathrm{ml} / \mathrm{kg} / \mathrm{min}$. These maximal energy expenditures are comparable to those typically observed in exercising patients with congestive heart failure, albeit 5.5 miles lower at sea level! Furthermore, the geographical location of $\mathrm{Mt}$ Everest at a latitude of $28^{\circ} \mathrm{N}$ results in a barometric pressure that is considerably higher than if it were located near one of the poles. The climatic idiosyncrasy of this "equatorial bulge" is fortunate in that, without it, a climber would not be able to summit without supplementary $\mathrm{O}_{2}{ }^{8}$

It is, however, somewhat discouraging to note that the physical challenge of climbing Mt Everest without supplementary $\mathrm{O}_{2}$ is becoming more difficult as the summit appears to be increasing in height at a rate of $3 \mathrm{~cm} /$ year and steadily moving north eastward at $6 \mathrm{~cm} /$ year (Geological Society, personal communication). This is a consequence of it being located on the great fault system, which continues to push India under Nepal and China thus creating the Himalayas. These data required the initial measurement of the summit, which in itself has proved one of the most formidable geological challenges since the first attempt using vertical triangulation by James Nicolson during 1847$1849(8840 \mathrm{~m})$, which failed to take into account the deflection of the vertical produced by the Himalayan chain, the discrepancy between geoid and ellipsoid, and refraction of the atmosphere. The Chinese National Bureau of Surveying and Mapping and the Italian National Research Council have subsequently performed what is arguably the most accurate measurement of the summit using laser distance meters, theodolites, and satellite positioning systems. The value reported in 1992 was $8848.65(0.35) \mathrm{m}$ above sea level (inclusive of the snow on the summit measured as $2.55 \mathrm{~m}$ ). These facts raise the irresistible question of how much longer an oxygenless ascent will remain humanly possible.

Figure 1 (based on the data presented in table 1) clearly illustrates that systemic $\mathrm{O}_{2}$ transport is exquisitely sensitive 


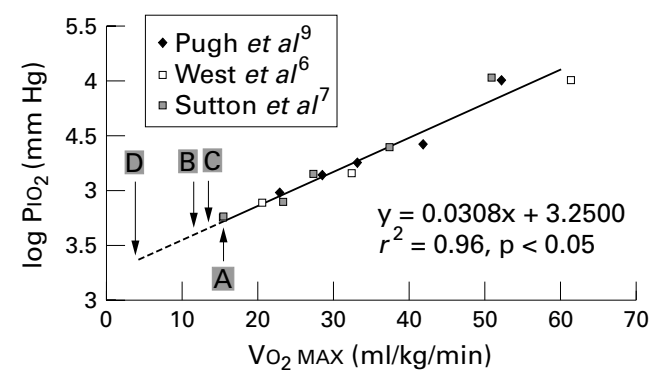

Figure 1 Decline in maximal oxygen uptake ( $\left.\mathrm{VO}_{2} \mathrm{MAX}\right)$ expressed relative to total body mass with a decrease in the inspired partial pressure of oxygen $\left(P_{I O_{2}}\right)$. Data on the ordinate are log transformed and based on the individual data points presented in table 1. Point $A$ illustrates existing data for VO,MAX obtained during two "simulated" ascents of Mt Everest. Summit $\mathrm{PIO}_{2}(42.5-43 \mathrm{~mm} \mathrm{Hg})$ was obtained (a) at a terrestrial altitude of $6300 \mathrm{~m}$ with subjects inspiring $14 \% \mathrm{O}_{2}$ during the American Medical Research Expedition to Everest ${ }^{\circ}$ and (b) in a decompression chamber during Operation Everest II.' The regression line has been extrapolated to predict the corresponding PIO, values at: (a) 3.5 METs (assuming that 1 $M E T=3.5 \mathrm{ml} / \mathrm{kg} / \mathrm{min}$ ), which equates to the lowest maximal value required for successful ascent of the last $100 \mathrm{~m}$ of $\mathrm{Mt}$ Everest during the summer months (barometric pressure about $251 \mathrm{~mm} \mathrm{Hg}$ ) assuming an average energy expenditure equivalent to $85 \%$ of a climber's VO $O_{2} M A X$ (point B); (b) 3.9 METs which is considered the lowest maximal value required for a winter ascent such as that achieved by Sherpa Ang Rita (point $\mathrm{C}$ ) which is considerably more difficult despite a mere $<1 \mathrm{~mm} \mathrm{Hg}$ reduction in the $\mathrm{PIO}_{2}$ compared to (a); (c) 1 MET which equates to a climber's basal metabolic rate (point $D$ ).

to a decline in $\mathrm{PiO}_{2}$ primarily because of a decrease in alveolar $\mathrm{PO}_{2}\left(\mathrm{PAO}_{2}\right)$. Extrapolation of this relation predicts the $\mathrm{PIO}_{2}$ at a variety of energy expenditures ranging from 1 metabolic equivalent (MET) to 3.9 METS compared with the measured maximum of about 4.5 METS (assuming 1 MET $=3.5 \mathrm{ml} / \mathrm{kg} / \mathrm{min}$ ). Whole body $\mathrm{VO}_{2} \mathrm{MAX}$ is expressed in relative terms and further reduced to METS to normalise for the unavoidable differences between studies in subject body mass, which is an undoubted confounding variable during attempts to fit pooled data.

The value of 3.5 METS (point B on fig 1) was selected because 3 METS is considered the minimum energy expenditure required for a safe ascent to the summit during the summer months assuming that the climber is working at about $85 \%$ of his maximum, which is not unreasonable (J S Milledge, personal communication). Messner's total body mass including equipment was reported to be $74 \mathrm{~kg},{ }^{10}$ which at an ascent rate of $2 \mathrm{~m} / \mathrm{min}$ during the last $100 \mathrm{~m}$ of the climb would have resulted in a power output close to $150 \mathrm{~kg} / \mathrm{m} / \mathrm{min}$. According to the data of West et al ${ }^{6}$ and the aforementioned assumption, this submaximal effort would have required a $\mathrm{VO}_{2} \mathrm{MAX}$ of approximately 3.5 METS.

Table 1 Measured values of maximal oxygen uptake (VO丶MAX) and inspired partial pressures of oxygen $\left(\mathrm{PIO}_{2}\right)$ at various altitudes in three landmark investigations ${ }^{679}$

\begin{tabular}{|c|c|c|c|c|}
\hline Study & $\begin{array}{l}\text { Sample size } \\
(n)\end{array}$ & $\begin{array}{l}\text { Altitude }(\mathrm{m}) \\
\text { Model atmosphere }\end{array}$ & $\begin{array}{l}\mathrm{PIO}_{2} \\
(\mathrm{~mm} \mathrm{Hg})\end{array}$ & $\begin{array}{l}\mathrm{VO}_{\mathrm{O}_{2} \mathrm{MAX}} \\
(\mathrm{ml} / \mathrm{kg} / \mathrm{min})\end{array}$ \\
\hline \multirow[t]{5}{*}{ Pugh et al ${ }^{9}$} & 3 & Sea level & 147.1 & 52.1 \\
\hline & 3 & 4650 & 82.3 & 41.7 \\
\hline & 3 & 5800 & 69.7 & 33.0 \\
\hline & 3 & 6400 & 62.2 & 28.5 \\
\hline & 1 & 7440 & 53.0 & $22.8^{\star}$ \\
\hline \multirow[t]{4}{*}{ West $e t a l^{6}$} & 5 & Sea level & 147.1 & 61.3 \\
\hline & 8 & 6300 & 63.7 & 32.4 \\
\hline & 6 & 8050 & 48.5 & 20.6 \\
\hline & 2 & 8848 & 42.5 & 15.3 \\
\hline \multirow{5}{*}{ Sutton $e t a l^{7}$} & 8 & Sea level & 150.0 & 50.8 \\
\hline & 8 & 4300 & 80.0 & 37.3 \\
\hline & 7 & 6500 & 63.0 & 27.2 \\
\hline & 5 & 8100 & 49.0 & 23.3 \\
\hline & 5 & 8848 & 43.0 & 15.4 \\
\hline
\end{tabular}

${ }^{\star}$ One subject in the original paper was excluded from analysis because of infectious illness at the time of exercise testing.

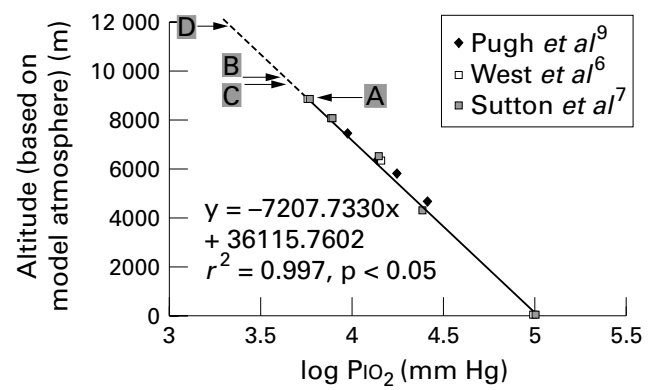

Figure 2 Inverse relation between altitude and the inspired partial pressure of oxygen $\left(\mathrm{PIO}_{2}\right.$ ) based on the individual data points presented in table 1. Data on the abscissa are log transformed. Point $A$ indicates the present altitude of $M t$ Everest measured at $8848.92 \mathrm{~m}$. The regression line has been extrapolated to predict the corresponding altitudes at the respective $\mathrm{PIO}_{2}$ values predicted in fig 1 (point $B=9972.7 \mathrm{~m}$, point $C=$ $9662.1 \mathrm{~m}$, and point $\mathrm{D}=11913.9 \mathrm{~m})$.

Seasonal variations in barometric pressure at these extreme altitudes have a major impact on systemic $\mathrm{O}_{2}$ transport and are thus of considerable physiological significance. Previous theoretical calculations have identified that a mere $4 \mathrm{~mm} \mathrm{Hg}$ decrease in summit barometric pressure would reduce a climber's predicted $\mathrm{VO}_{2} \mathrm{MAX}$ by about $10 \%{ }^{8}$ Thus, point $\mathrm{C}$ on fig 1 refers to the predicted $\mathrm{VO}_{2} \mathrm{MAX}$ of a climber based on the previous assumptions attempting to summit during the winter months, a remarkable feat that was achieved on 22 December 1987 by Sherpa Ang Rita. Retrospective analyses indicated that the summit pressure during this ascent was $247 \mathrm{~mm} \mathrm{Hg},{ }^{11}$ only 3-4 $\mathrm{mm} \mathrm{Hg}$ lower than that observed during the American Medical Research Expedition to Everest (AMREE) ${ }^{6}$ and Operation Everest $\mathrm{II}^{7}$ (point A).

Incorporating this information into the linear function presented in fig 2 (based on the data summarised in table 1), we can identify the corresponding altitude at each of the respective $\mathrm{PIO}_{2}$ values which equates to $9972.7 \mathrm{~m}$ (3.5 METS, point B), $9662.1 \mathrm{~m}$ (3.9 METS, point C), and $11913.9 \mathrm{~m}$ (1 MET, point D).

Assuming a constant growth rate of $3 \mathrm{~cm} /$ year and present (2001) height of $8848.92 \mathrm{~m}$, a climber with a $\mathrm{VO}_{2}$ MAX of 3.5 METS would therefore have to make his assault on the summit during the summer months before about $39460 \mathrm{AD}$. A winter ascent would need to be launched before $29107 \mathrm{AD}$. By about $104167 \mathrm{AD}$, a climber's $\mathrm{VO}_{2} \mathrm{MAX}$ on the summit would equate to his basal metabolic rate measured at sea level, emphasising the futility of any summit bid. Incidentally, these dates could be extended by another 85 years if the snow on the summit melted.

A climber with a sea level $\mathrm{VO}_{2} \mathrm{MAX}$ that is comparatively higher than the values incorporated in fig 1 could further extend the theoretical timescale of an oxygenless ascent. Data obtained during $\mathrm{AMREE}^{6}$ clearly indicate a slight leftward displacement of the $\mathrm{VO}_{2} \mathrm{MAX} \alpha \mathrm{PIO}_{2}$ curve, effected in part by a $24 \%$ higher sea level $\mathrm{VO}_{2} \mathrm{MAX}$ when compared with the data obtained by Pugh et al. ${ }^{9}$ Hypoxic chemosensitivity may also affect these predictions, with previous studies indicating that climbers with a "brisk" hypoxic ventilatory response are capable of reaching higher altitudes on the mountain. ${ }^{12}$ However, the hyperventilatory responses observed at high altitude are energetically more demanding, accounting for $26 \%$ of an individual's $\mathrm{VO}_{2} \mathrm{MAX}$ at $5050 \mathrm{~m}$ compared with $5.5 \%$ at sea level (assuming a mechanical efficiency of 5\%). ${ }^{13}$ Thus it would appear that the mechanical power of breathing may impair a climber's ability to perform external work on the mountain. The limits for reaching the theoretical summit are also affected by subtle changes in barometric pressure as the comparative example of Messner's summer ascent versus Sherpa 
Ang Rita's winter ascent clearly indicates; a successful winter bid would have to occur about 10 millenia before a summer bid despite a mere $3-4 \mathrm{~mm} \mathrm{Hg}$ difference in summit pressure. More pronounced seasonal changes in summit pressure, which can differ by up to as much as $11.5 \mathrm{~mm}$ $\mathrm{Hg}$ at Everest's present altitude, could further reduce the theoretical timescale of an oxygenless ascent. ${ }^{14}$ Changes in the geological (summit growth rate) and climatic $\left(\mathrm{FIO}_{2}\right.$ and barometric pressure $\alpha$ altitude relation possibly as the result of global rewarming) assumptions on which these calculations are based have obvious implications for summit dates; whether the predictions are correct, only time will tell!

Despite its appeal, the risks inherent in an ascent to such extreme altitudes by "fair means" are quite considerable and can increase a climber's susceptibility to hypoxic brain damage, as studies showing clear evidence for residual impairment of central nervous system function after return to sea level ${ }^{15}$ would seem to suggest. Furthermore, recent epidemiological data clearly indicate that an oxygenless ascent/descent of Mt Everest and K2 is associated with more fatalities ${ }^{16}$ probably because of the proposed therapeutic benefits of supplemental $\mathrm{O}_{2}$ as a means of reducing the incidence of "medical" (related to altitude illness) and "traumatic" (caused by accident as the result of misjudgement) deaths. ${ }^{17}$ Thus, although high altitude mountaineers may find some reassurance that, at least for the next 40 millennia, an oxygenless ascent will have some chance of succeeding, the ethical implications of such a remarkable feat warrant due consideration. The physical and intellectual challenge posed by Everest lives on!
Hypoxia Research Unit, Health and Exercise Sciences Research

Laboratory, School of Applied Sciences, University of Glamorgan,

Pontypridd, South Wales CF37 1DL, UK

dbailey1@glam.ac.uk

1 Asimov I. Asimov's new guide to science. Revised ed. London: Penguin Group, 1984:191-231.

2 West JB. High life: a history of high-altitude physiology and medicine. New York: Oxford University Press, 1998.

3 Hinchcliff TW. Over the sea and far away. London: Longmans Green, 1876: $90-1$.

4 Barcroft J, Douglas CG, Kendal LP, et al. Muscular exercise at low barometric pressures. Arch Sci Biol Napoli 1931;16:609-15.

5 Messner R. Everest: expedition to the ultimate. London: Kaye and Ward, 1979 : 180 .

6 West JB, Boyer SJ, Graber DJ, et al. Maximal exercise at extreme altitudes on Mount Everest. F Appl Physiol 1983;55:688-98.

7 Sutton JR, Reeves JT, Wagner PD, et al. Operation Everest II: oxygen transport during exercise at extreme simulated altitude. F Appl Physiol 1988;64: 1309-21.

8 West JB, Wagner PD. Predicted gas exchange on the summit of Mt. Everest. Respir Physiol 1980;42:1-16.

9 Pugh LGCE, Gill MB, Lahiri S, et al. Muscular exercise at great altitudes. $\mathcal{F}$ Appl Physiol 1964;19:431-40.

10 Pugh LGCE, Sutton JR. Everest then and now. In: Sutton JR, Houston CS, Jones NL, eds. Hypoxia, exercise, and altitude: proceedings of the Third Banff International Hypoxia Symposium. New York: AR Liss, 1983:415-28.

11 Ward MP, Milledge JS, West JB. High altitude medicine and physiology. London: Arnold, 2000:28.

12 Schoene RB, Lahiri S, Hackett PH, et al. Relationship of hypoxic ventilatory response to exercise performance on Mount Everest. F Appl Physiol

13 Cibella F, Cuttitta G, Romano S, et al. Respiratory energetics during exercise at high altitude. F Appl Physiol 1999;86:1785-92.

14 West JB, Lahiri S, Maret KH, et al. Barometric pressures at extreme altitudes on Mt. Everest: physiological significance. F Appl Physiol 1983;54:1188-94. 15 Hornbein TF, Townes BD, Schoene RB, et al. The cost to the central nervous system of climbing to extremely high altitude. N Engl f Med 1989;321: 1714-19.

16 Huey RB, Eguskitza X. Supplemental oxygen and mountaineer death rates on Everest and K2. $尹 A M A$ 2000;284:181.

17 Pollard A, Clarke C. Deaths during mountaineering at extreme altitude. Lancet 1988;1:1277. 